who is engaged on theoretical and experimental investigations in hydrodynamics and acoustics with special application to the reduction of ship noise and to the examination of cavitation phenomena; H. L. Green (Ministry of Supply), who has made important contributions to the study of particle suspensions and has developed this branch of physics to a very high degree of precision; J. S. Hey (Army Operational Research Group, War Office), who, in the course of his work on radar and the ionosphere, has carried out important investigations on abnormal radiations from the sun and the galaxy and on echoes due to meteors; Dr. H. London (Ministry of Supply), a physicist whose outstanding work before the War was on the effect of high frequencies on supra-conductivity ; more recently, he has worked on the separation of stable isotopes, and has achieved results of considerable practical and theoretical importance in the separation of carbon-thirteen by low-temperature distillation; A. R. Rangabe (Admiralty), who was concerned prior to the War with the development in industry of electronic tubes of all descriptions; his ingenuity and flair for developing manufacturing techniques, and his understanding of the problems and difficulties in manufacture, have particular significance at the present time; Dr. E. Roberts (Ministry of Supply) has a long and successful record of important and fundamental work on diverse aspects of the chemistry and production of explosives.

National Institute of Sciences of India: New Fellows

AT the peeting of the National Institute of Sciences of Indig on January 4, 1949, the following elections were announced. Honorary Fellows : Prof. Louis de Broglie, professor of theoretical physics, Poincaré Institute, Sorbonne, Paris; Prof. Hans von Euler, emeritus professor of chemistry, University of Stockholm; Dr. Harlow Shapley, director of Harvard Observatory, Cambridge, Mass.; Prof. Georg Tischler, Botanical Institute, University of Kiel. Ordinary Fellows: Dr. J. L. Bhaduri, lecturer in zoology, University of Calcutta; Dr. S. Bhagavantam, scientifie liaison officer for India in the United Kingdom; Dr. S. K. Chakrabarty, director, Colaba and Alibag Observatories, Bombay; Dr. D. Chakravarti, lecturer in chemistry, University of Calcutta ; Dr. M. Damodaran, assistant director, National Chemical Laboratories, Delhi ; Dr. B. K. Das, professor of zoology, Osmania University, HyderabadDeccan; Dr. Kurien Jacob, palæobotanist, Geological Survey of India, Calcutta ; Dr. T. S. Mahabale, lecturer in botany, Royal Institute of Science, Bombay; Dr. H. K. Mitra, refractories engineer, Tata Iron and Steel Co., Ltd., Jamshedpur; Dr. K. Mitra, officer in charge, Nutrition Scheme, Public Health Lab. oratories, Patna; Dr. A. H. Pandya, director, Hindusthan Aircraft, Bangalore; Dr. N. Parthasarathy, geneticist, Indian Agricultural Research Institute, New Delhi ; Dr. C. Racine, professor of mathematics, Loyola College, Madras; Dr. K. C. Sen, director, Indian Dairy Research Institute, Bangalore; Dr. R. S. Varma, reader in mathematics, University of Lucknow.

\section{Production of Radioactive Isotopes in Britain}

THE large atomic pile (BEPO) at the Atomic Energy Research Establishment, Harwell, has begun opelating for the production of radioactive isotopes. When it is working at full power later this year, it will be able to produce all the artificial radioactive isotopes required in Great Britain by medical, indus- trial and other research workers. More isotopes will also be available for export, and it is expected that a steadily increasing demand for them will develop overseas. Materials irradiated in the new pile will be twenty times more active than those so far irradiated in the first and smaller pile. The new pile has. a rated output of $6,000 \mathrm{~kW}$. and was designed primarily for experimental purposes. The smaller pile, designed to develop about $100 \mathrm{~kW}$. of heat, started up in August 1947 and has been producing radioactive isotopes since September of that year. Present production is about a hundred and fifty specimens a month.

\section{Vegetation-types Map of Tanganyika

THE Geographical Regiew has published a reprint of an article frefaro January 1949 issue entitled "A Vegetation yyes Map of Tanganyika", by the late Clemprf Gillman. This study of the natural vegetati Mf Tanganyika Territory by a man who had prolound knowledge of the country and of its pefand is one that should be used as a basis for wise planning, and development. The classification is strictly physiognomic and provides an essential basis for further ecological and geographical investigations. The vegetation of the greater part of Tanganyika Territory is a mixture of woodland or bushland with grassland, the distribution being primarily determined by variations of soil and water conditions and the use made of them by man, although, as the author points out, topography and tectonics influence the climate and distribution of vegetation. The main types shown on the coloured map on a scale of $1: 2,000,000$ include forest, woodland, bushland and thicket, grassland, permanent swamp vegetation, desert and semi-desert, and vegetation actively induced by man in native and non-native cultivations. The term "actively induced vegetation" includes the mixed and constantly changing pattern of cultivated crops, pastures and interspersed remnants of the original vegetation and of scattered small areas of secondary growth. Complexes of vegetation occurring in close conjunction are shown on the map symbolically, using the colour of the dominating type for the ground colour with intrazonals or complexes shown by circles or dots in the colour of their type. Sequences of vegetation types caused by regularly repeated physiographic or hydrographic conditions are shown as "catenas"-a word originally applied to soils in East Africa. The map brings out at a glance the small remnants of evergreen forest left on the main watersheds, and the author stresses the urgency of the threat to the country's water resources. The map also rectifies a commonly held exaggerated view of the size of alien plantations and farming settlements, which appear as tiny specks compared with the great extent of native-cultivated land.

\section{Statistical Estimation}

THE current mather frtical theories concerned with the estimation of $0 \mathrm{r}$ more unknown parameters in a frequeng findion have been the occasion of mucle conf roversy, and the absence of a systematic revie of this field at a sufficiently elementary level has M. 2 a serious obstacle to the student. Two recent articles by Dr. Leon Solomon published in the Journal of the Institute of Actuaries Students' Society (7, 144 and 213) go a long way towards meeting this need, and form a most welcome addition to the literature. The first article is chiefly concerned with 'point' estimation. The concept of sufficiency is discussed, the minimum-variance theorem is proved, and 